\title{
Using a low-cost bluetooth torque sensor for vehicle jerk and transient torque measurement
}

Proc IMechE Part D:

J Automobile Engineering

$\mathrm{I}-15$

(c) IMechE 2019

Article reuse guidelines:

sagepub.com/journals-permissions DOI: $10.1177 / 0954407019861613$

journals.sagepub.com/home/pid

(SAGE

\author{
Peter Tawadros, Mohamed Awadallah $₫$, Paul Walker and Nong Zhang
}

\begin{abstract}
This paper presents the use and development of a specific wireless torque measurement system that is used to obtain the transient torque performance of vehicle transmissions. The torque sensor is strain-based, using surface-mounted strain gauges on a prop shaft. The gauges are connected to a compact printed circuit board, which is clamped to the shaft next to the strain gauges using a three-dimensional printed housing. The printed circuit board contains an amplifier, low-pass filter, analog-to-digital converter, microcontroller and bluetooth transceiver. The printed housing is impact resistant carbon-reinforced nylon and securely retains the printed circuit board and the battery powering the device. The transmitted torque data are received by a transceiver, which is interfaced to a PC through an RS-232 connection. NI LabVIEW is used to process, display and save data. The wireless torque sensor was installed to the Unit Under Test at the output shaft of the five-speed manual transmission. The Unit Under Test was installed on a dynamometer for verification purposes and the transient torque was recorded under various operational conditions. The transient output torque of the manual transmission is measured and compared with results obtained from simulations performed under similar operating conditions. The two sets of transient responses show a good correlation with each other and hence demonstrate that the torque sensor meets the major design specifications. The data obtained will be used to enhance the fidelity of the software model.
\end{abstract}

\section{Keywords}

Gear shift quality, LabVIEW, manual transmission, rotary shafts, torque-fill, torque hole, vehicle, torque measurement, wireless torque sensor

Date received: 26 September 2018; accepted: 4 June 2019

\section{Introduction}

This work is part of a broader project, the aim of which has been to develop a low-cost mild hybrid vehicle ideally suited to the developing markets of Asia, the MENA (Middle East and North Africa) region and sub-Saharan Africa, where penetration of vehicle electrification has been largely insignificant to date. Our goal has been to create a mild hybrid vehicle with favourable emissions and drivability performance, at a price point that makes sound business sense in these very cost-sensitive markets. In achieving this goal, we have created a new low-cost hybrid electric powertrain that is robust and simple, while retaining similarity with the typical vehicles found in the target markets. For more information on the development of this powertrain, we direct the reader to Awadallah et al. ${ }^{1,2}$ In developing and refining the powertrain, we used a hardware-in-loop (HIL) test bench to rapidly develop control algorithms. Torque measurement was required to validate and improve both simulation and HIL modelling. To achieve this, a measurement device that could be quickly and easily swapped between the road-going vehicle and the HIL development platform was required. This approach has multiple benefits; it gives high confidence in the relative accuracy of measurements, is cost-effective and minimizes any modification of the system to accommodate custom-designed torque measurement devices.

Faculty of Engineering and Information Technology, School of Mechanical and Mechatronic Systems, University of Technology Sydney, Ultimo, NSW, Australia

\section{Corresponding author:}

Mohamed Awadallah, Faculty of Engineering and Information Technology, School of Mechanical and Mechatronic Systems, University of Technology Sydney, 8I Broadway, Ultimo, NSW 2007, Australia.

Email: mohamed.m.awadallah@student.uts.edu.au; eng.m.zakaria@gmail.com 
Our low-cost hybrid electric powertrain utilizes a traditional manual transmission (MT), which was selected for this project for a number of strong reasons. First, the MT still offers the best efficiency/cost ratio of any transmission. It has proven to be superior in terms of its efficiency, and it is also representative of the typical vehicle in our target markets. Consequently, the vehicles in which they are installed demonstrate favourable fuel consumption. In saying this, the load applied on the MT plays a significant role in the level of this efficiency. A value of up to $97 \%$ efficiency can be reached over a typical drive cycle.

The most prominent weakness of the MT is the torque hole developed during a gear change, which is a result of the disengagement of the transmission from the power plant (engine) required to execute gear selection. It became apparent that exploring this weakness to develop methods to eliminate the problem while maintaining a cost advantage would yield a significant benefit to the project. As such, it became a project goal to investigate MT drivability by exploring vibration characteristics. This required high-resolution torque measurements to validate acquired data against software models. No suitable sensor could be found for this application within the project constraints.

A number of torque sensing options were investigated. The sensors commonly available and disclosed in the literature fall into three main categories. These are passives, actives and angular displacement metres. Passive sensors utilize resistive, capacitive or inductive elements to sense shaft strain. They require conditioning circuits and a power supply to operate. Typically, the power is supplied by slip rings, rotary transformers or an inductive power loop. Active sensors use magnetostrictive, optical or piezoelectric sensing elements. Angular displacement metres may use Hall effect, capacitance or optical principles.

In most cases, these torque sensors are physically characterized in one of two types. In the first type (inline), torque sensors are inserted into the powertrain and form part of the power transmission path. The sensing element rotates and deforms torsionally, and the deformation or angular displacement is measured. In the inline type, the powertrain must be modified to allow for the installation of the sensor. This can be difficult to do in the field, or not possible operationally, as significant modifications to the system are typically required for installation. However, because the torque sensor is part of the transmission path, its accuracy is usually high.

In the second type (split), a sensing element is mounted on the shaft, and a transceiver and/or power supply is mounted on a stationary element. In the case of non-optical sensing elements, the element is powered by inductance or slip rings, requiring some kind of rotating bearing assembly at the shaft. Signal conditioning and power is supplied by the stationary assembly. In the case of optical sensing, a stationary transceiver is usually mounted to observe the optical effect of deflection. The drawbacks of split sensors are that they can be susceptible to electrical noise, environmental contamination and relative movement of the powertrain - such as in an automotive application where the powertrain is required to be flexible mounted to improve noise, vibration and harshness (NVH) characteristics. Slip rings, inductive loops, optical transceivers and wire runs may all become misaligned or break if not correctly installed, or if an unexpected relative movement occurs.

In our application, the powertrain could not be easily modified to use an inline torque sensor, and a split torque sensor was not practical due to the small installation space available and the large relative movement of the powertrain. The solution to this problem required a custom-built transducer, which was developed from a design previously implemented by our team at the University of Technology Sydney.,

In this paper, the 'Vehicle jerk' section presents a brief introduction of vehicle transmission technology and benchmarking measurements relating to jerk and NVH. The wireless torque measurement system is presented in overview in 'Module architecture' section. The details of the major components and new developments implemented within the new sensor, as compared to Zhang et al., ${ }^{3}$ are provided. The wireless torque sensor was installed at the output shaft of the transmission fitted in the powertrain to capture the transient torque under various operating conditions. The 'Module testing' section describes the testing of the sensor. Sections 'Powertrain selection' and 'Simulation model development' describe the modelling and prototyping environment used for the development of the hybrid vehicle, as well as benchmarking scenarios conducted in the simulation. In the 'Comparative results' and 'Vehicle jerk estimation using wireless torque sensor' sections, we discuss transient transmission output torque results observed from the sensor in comparison to the model's simulated output and use the information to quantify vehicle jerk, which is derived from torque. The quantification of experimentally derived jerk and examination of the ability of the model to predict jerk characteristics was a major outcome of the presented research.

\section{Vehicle jerk}

An automotive powertrain is a complex, non-linear system comprised of many hundreds of components that contribute to its overall function. The main components that comprise this system include a power plant (either an engine or electric motor), a clutch or torque converter (depending on manual or automatic transmission, respectively) and the transmission (or often, transaxle). Along with these components are included the final drive, differential, drive shaft and the driven wheels. The power plant provides both torque and rotational velocity that directly drives the wheels. In MTs, the purpose of the clutch is to couple/decouple 
the gearbox from the power plant and provide a continuous path for torque transmission. In coupling and decoupling, discontinuities and oscillations are introduced which manifest to the vehicle occupants as a jerk. In an automatic transmission, the torque converter is by its nature a hydrodynamic device. It has a continuously variable rotation ratio but serves the same role as a clutch would in an MT system. ${ }^{5}$ Because of its fluidic coupling, torque oscillations and resultant jerk are highly damped, and therefore the shifting quality is noticeably enhanced.

The transmission, being one of two primary assemblies within the powertrain, is required to compensate for the limited conditions under which the power plant (engine) can operate efficiently, matching inertia through torque multiplication. Its primary function is to provide the driver-requested torque to the road interface while maximizing efficiency and ride quality. ${ }^{6}$ In its most elemental form, the transmission consists of a plurality of gear reductions, a gear selection (gear shift) device, and a mechanism to enable the coupling and decoupling of the motive power source from the load path. The design of the powertrain systems, and in particular, control systems, is a primary means available to ensure the vehicle operates with high efficiency and optimized ride quality. Control of the non-linear system, particularly noting and adjusting the transient behaviour of the system during gear changes, is essential to achieving low-jerk, high ride quality results that are valued by the vehicle occupants.

Transient behaviour during the shift period, such as jerk, generally arises from discontinuities present in the system. These discontinuities may be speed - such as the difference in rotational speed between driving and driven gear pairs; torque - such as the difference between output torque in the current gear and the target gear; or inertia - such as the difference between engine inertia and vehicle inertia. Minimizing these discontinuities improves the transient response of the powertrain. ${ }^{7}$ To achieve improved transient response, a number of different technologies have been developed in the area of automotive transmissions. These are summarized in Table 1.

The MT is very easy to manufacture, having few and relatively simple parts. It is reliable and easy to maintain. The automated manual transmission (AMT) and the dual-clutch transmission (DCT) were developed in response to the growing need for an efficient alternative to the automatic transmission, in order to meet the twin targets of increasingly tightened emissions legislation and increasing consumer expectations in terms of driveline comfort. By reclaiming control of the gear selection process from the driver, shift maps or algorithms can be tailored towards improved emissions, improved economy, improved performance or a combination of these attributes. Automatic transmissions are particularly well suited to this. Conversely, MTs coupled to non-hybrid (conventional internal combustion only) powertrains are not well-suited to automated control. Automation typically results in increased jerk and slower shift time as compared to a skilled driver, primarily due to difficulty in creating accurate clutch-wear models. The inclusion of a secondary power source downstream of the transmission in a hybrid vehicle provides the opportunity to improve this characteristic significantly.

\section{Measuring and improving shift quality}

Measuring transmission shift quality has aspects that may be defined empirically, analytically, objectively as well as subjectively. An example of this is apparent when the longitudinal acceleration of a vehicle is measured. Quantitative values can be attained for longitudinal acceleration during a gear shift. Also along the quantitative sense, there is a measurable torque interruption to the wheels during a standard upshift in an MT. Figure 1 demonstrates this concept. From a subjective viewpoint, a user observation can be made about the performance or behaviour of the vehicle, typically seen as a pitching of the vehicle about its transverse axis or by a characteristic behaviour referred to as a 'bunnyhopping'. Once again, user observation can be a marker of measurement, ranging from slight rider discomfort all the way to uncontrollable handling and poor manoeuvrability. These subjective observations can be correlated to quantitative measurements. By modelling the system, numerical relationships may be defined to allow optimisation of dynamic performance or NVH.

The availability of torque through a powertrain to the road-tyre interface is directly related to dynamic

Table I. Transmission type (summary).

\begin{tabular}{ll}
\hline Automatic transmission (AT) & $\begin{array}{l}\text { High manufacturing cost. Smooth gear-change characteristics - no need for } \\
\text { supplementary torque fill } \\
\text { Cheaper than automatic but lower torque capacity. No discrete gear changes } \\
\text { Continuously variable transmission (CVT) }\end{array}$ \\
$\begin{array}{ll}\text { Dual-clutch transmission (DCT) } \\
\text { Hutomated manual transmission (AMT) }\end{array}$ & $\begin{array}{l}\text { Lower manufacturing cost - clutch and shift hub actuators may be } \\
\text { incorporated into the hybrid architecture. Poorest gear-change characteristics. } \\
\text { The motor must be placed after the first reduction }\end{array}$ \\
Manual transmission (MT) & $\begin{array}{l}\text { Lowest manufacturing cost. The motor can only be placed after the first } \\
\text { reduction }\end{array}$
\end{tabular}




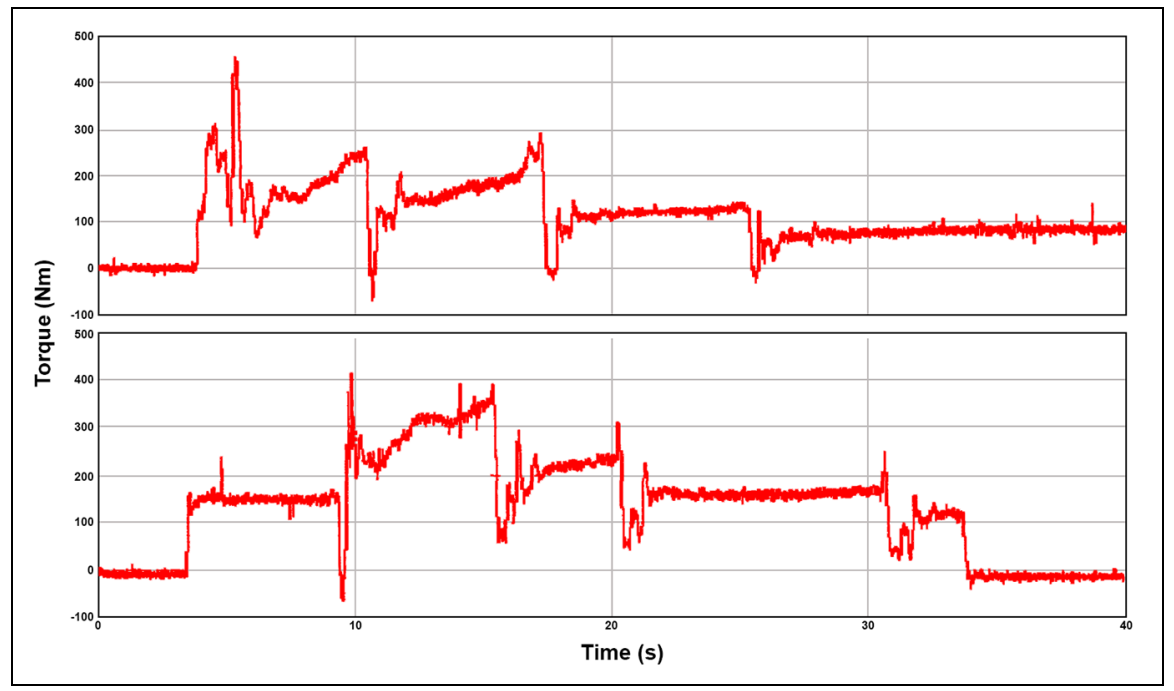

Figure I. Actual measured half shaft torque with fill-in, showing the different phases of the gear change. ${ }^{8}$

vehicle performance characteristics such as maximum speed, acceleration and gradability. The manner in which torque is delivered is directly related to vehicle drivability and comfort characteristics. Torque oscillations and step changes through a drivetrain are common sources of NVH. Measured torque oscillations can be correlated with parameters such as jerk, snap and higher motion derivatives. Human perception can be analysed using vibration dose value (VDV). These correlations can then be used in the system model as part of a HIL development platform, using torque measurement to optimize a wide variety of system characteristics. Achieving this relies on high-quality, reliable torque measurement.

Torque oscillations are caused by sudden changes in inertia, such as caused by clutch disengagement, or sudden changes in the equilibrium of the system (such as a rapid throttle actuation) combined with underdamped torsional systems through the powertrain. Damping within the powertrain is typically sourced from vibration absorbers such as rubber or hydraulic mounts (engine mounts, transmission mounts and subframe mounts), parasitic or drag losses in transmission components and clutch slip. In hydromechanical systems where torque is transmitted through fluid power, the fluid itself is also a source of damping, therefore the elimination of fluid couplings, as in a traditional MT, also reduces overall system damping, ${ }^{9,10}$ making accurate shift control strategies more critical to achieving acceptable NVH. The AMT attempts to address this by adding robotized clutch actuation, gear selection or both to an MT. Clutch feed-in and engine throttle modulation can be controlled using sophisticated control strategies to deliver a high degree of damping against torque oscillation. The AMT also offers the efficiency of the manual architecture and the convenience of automatic operation. However, it often delivers a poorer ride quality, slower shift times or both when compared to a skilled driver with a traditional MT. DCT further develops this concept by using two constantly meshed gear pairs on concentric shafts, and switches between two clutches to eliminate the 'torque hole'. It offers the same or better efficiency than an MT. However, the DCT is complicated and expensive to manufacture in comparison, and shift quality under low-speed conditions has been described as harsh. Table 1 presents summaries of the other main types of transmission technologies. ${ }^{11}$ Measuring torque oscillations provides a means for validating modelled behaviour and improving system behaviour and shift control strategy through simulation, implementation and validation.

\section{Module architecture}

Traditionally, torque monitoring in automotive applications usually has a high cost for the installation of modules, sensors and data logger. Besides the high cost, most commercially available modules offer little flexibility, making the deployment and maintenance a difficult process. In this context, the low-cost bluetooth module presented provides a number of advantages compared to others. For example, the ease and speed of maintenance, easy modification to fit a wide variety of configurations, ability to be quickly field-deployed without requirements for shaft removal, and insensitivity to axial or radial shaft movement. Created using three-dimensional (3D) printed carbon-filled nylon, the housing features low-density infill to create a light, heat resistant, robust, very low profile structure. The design of the housing speeds the development process by allowing simple parametric modification to suit a variety of shaft sizes and other physical constraints and adds no more than $25 \mathrm{~mm}$ to the diameter of the shaft. It fully encloses the printed circuit board (PCB) and battery pack, mitigating possibility of damage due to environmental exposure. The unenclosed componentry is limited only to the strain gauge and attached conductors, which can be protected using a suitable wrap. In 


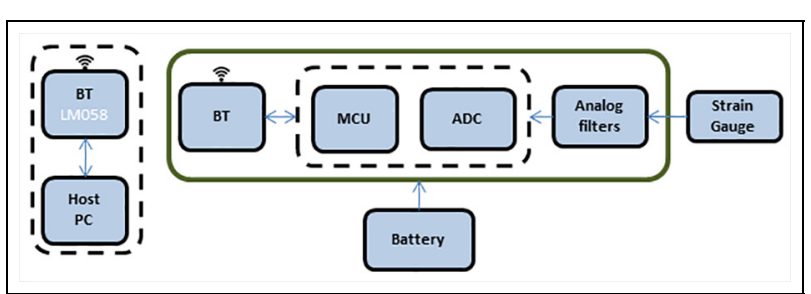

Figure 2. Torque module.

BT: bluetooth; MCU: microcontroller unit; ADC: analog-to-digital converter.

addition to this, module adopts the IEEE 802.15.1 standard for Bluetooth wireless communication. The standard has advantages related to scalability, reduced time for node inclusion and low cost. The communication protocol adopted is a flexible and inexpensive solution for building portable industrial monitoring and control systems. The module does all the data processing locally, transmitting to the base unit only the targeted parameters previously calculated. Thus, there is a large reduction in the amount of transmitted data, enabling real-time and dynamic monitoring of multiple shafts, even with a high data rate acquisition in the analog-to-digital converters (ADCs).

In an automotive application, the sensor is very wellsuited, as it is particularly well-adapted to be resistant to the types of environmental noise and contamination that are usually found in the vehicle underbelly such as heat and radiation, electrical noise from ignition systems and static discharge, vibration, and particle blasting or projectiles. The Bluetooth protocol is well suited for these applications.

To facilitate investigation of the torque profile of the MT equipped vehicle, the low-cost bluetooth torque sensor is installed on the prop shaft of the vehicle, which is rigidly connected to the output shaft of the transmission using a splined socket. Damping sources for vibration at this point include losses in the differential, play and losses in the constant velocity joints, and tyre deflection, which is by far the largest loss. However, because our work focuses on quantifying powertrain behaviour under gear changes, and particularly, the torque hole and oscillations, the tyre damping and losses could be neglected, as could other sources of damping downstream of the transmission.

The torque sensor schematic block diagram is provided in Figure 2, and the electrical schematic is provided in Appendix I (Figure 20). The sensor is based around the ATMega2561 microcontroller, which includes an 8-channel 10-bit ADC. Input from the Wheatstone bridge is low-pass filtered with a cut-off frequency of $1 \mathrm{kHz}$, and amplified using the TI INA326 instrumentation amplifier, which provides a $0-3 \mathrm{~V}$ signal to the ADC input. Anticipating a typical maximum shaft torque of $200 \mathrm{~N} \mathrm{~m}$ (based on physical engine characteristics), the module provides a torque resolution of $0.2 \mathrm{Nm}$, which is more than sufficient for the application. By selecting an appropriate strain gauge, the

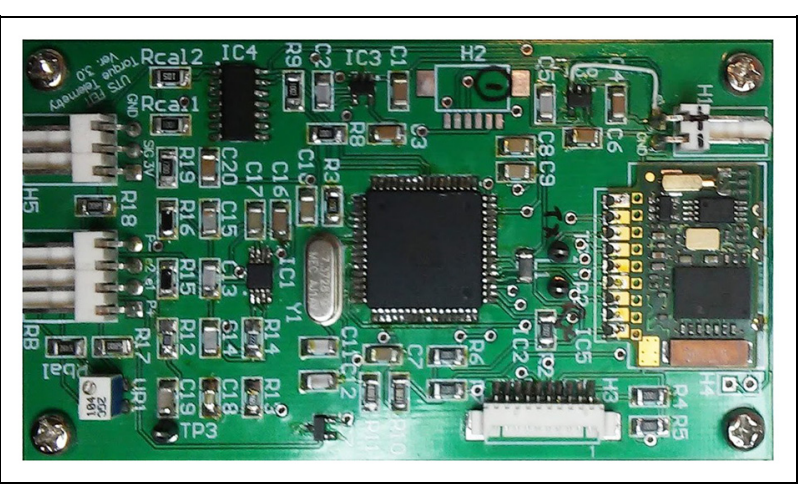

Figure 3. $P C B$ layout.

PCB: printed circuit board.

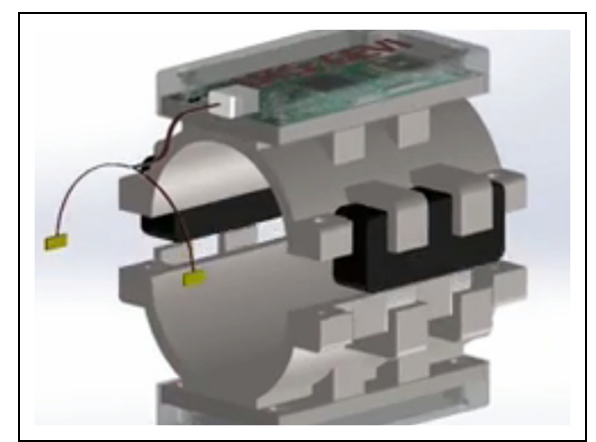

Figure 4. The torque sensor assembled in its housing.

module can be used successfully for applications up to $1000 \mathrm{Nm}$ shaft torque, at a resolution of $1 \mathrm{Nm}$. Above this level, it is suggested that a 12-bit ADC and 5 or $10 \mathrm{~V}$ analog signal level is substituted to maintain appropriate torque resolution. The ADC sample rate was desired to be set to $6 \mathrm{kHz}$, which concurs with a sample rate of approximately $1 \mathrm{kHz}$ per revolution at the maximum permissible rotational velocity. However, due to the bandwidth limitations of the bluetooth link, the ADC sample rate was lowered to $4.43 \mathrm{kHz}$, using sample-pair averaging to transmit a sample rate of $2.21 \mathrm{kHz}$. This arrangement still provided well over $1 \mathrm{kHz}$ per rotation sample rate, as shaft speed was limited to approximately $3000 \mathrm{r} / \mathrm{min}$. Future development of the sensor will increase the actual sample rate to achieve the desired $6 \mathrm{kHz}$.

The PCB was placed in its 3D printed housing (as shown in Figures 3 and 4) and spin-tested to $6000 \mathrm{r} / \mathrm{min}$ by clamping the housing on the shaft and conducting a maximum speed test. The housing and PCB showed no signs of failure after approximately $30 \mathrm{~min}$ of testing, although wire retention for the power supply was found to be insufficient, requiring field redesign. After some additional retention was installed, no further issues were observed.

A bluetooth data acquisition board with strain gauges (B-DAQ) is selected in this study to transmit data from the rotating shaft to a bluetooth receiver (LM058) using bluetooth communication. As shown in 


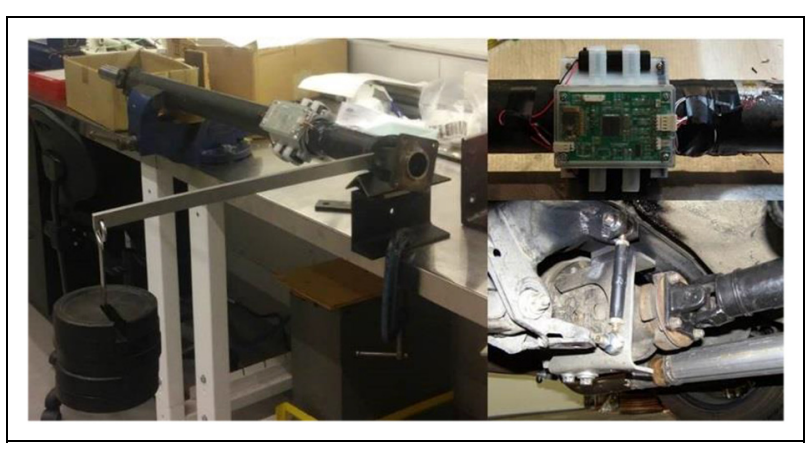

Figure 5. B-DAQ torque sensor calibration. B-DAQ: bluetooth data acquisition board.

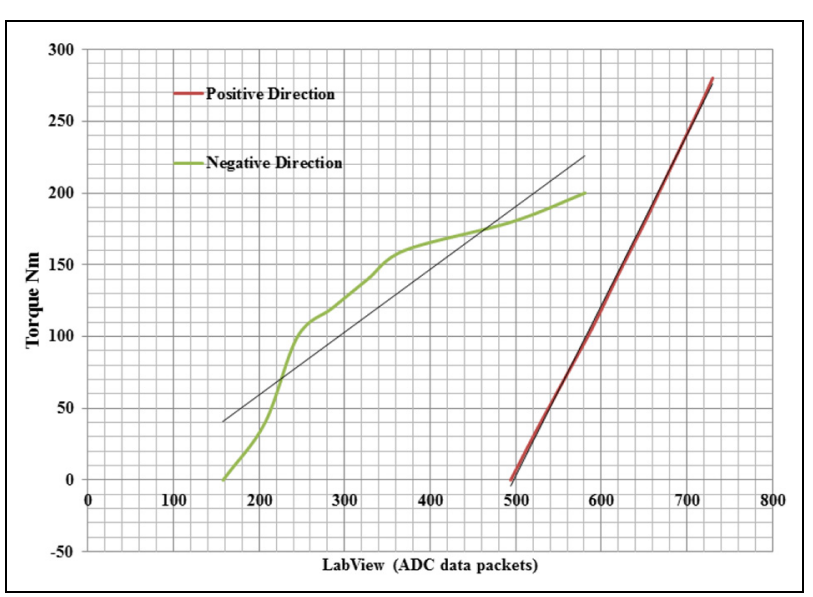

Figure 6. Real torque on the shaft VS LabVIEW displays bluetooth DAQ.

DAQ: data acquisition board.

Figure 5, a strain gauge is adhered to the shaft to transmit shaft torque, while the system is running. Power is supplied to the transmitter by a battery pack clamped within the housing to provide continuous measurements.
Because the torque-related elastic deformation of strain gauge sensors is displayed in terms of digital voltage, the relationship of torque applied to the shaft and the voltage from the sensor display should be calibrated before implementation (shown in Figure 6). The calibration is used in the programme code for B-DAQ in LabVIEW

Figure 7 shows the control panel of the real-time test rig for setting up important parameters such as torque, port number and so on. The result of the output shaft torque can be displayed and plotted through the instruments in the layout. The results can also be logged using recorders. Recorded data can be exported to MATLAB for further analysis.

In this manner, the setup as detailed allows gearchange events to be fully stored as data. Signal analysis of torque profiles is interactively available in real-time while the test is running, allowing monitoring and evaluation functions during the experiment.

\section{Strain gauge}

Four $350 \mathrm{ohm}$ metal-foil strain gauges were bonded to the shaft surface to comprise a four active element Wheatstone bridge. Two gauges were aligned at $+45^{\circ}$ to the rotation axis and the other two aligned at $-45^{\circ}$, to maximize their sensitivity to the torsional strain. They were arranged in pairs with the pairs positioned on opposite sides of the shaft, directly opposite to each other. This arrangement cancels any output due to shaft bending or temperature variations.

The system was calibrated statically using weights applied to a radius arm to create a known torque input to the shaft. In equation (1), strain is expressed in microstrain and $\mathrm{F}$ is the gauge factor of the gauges (approximately $=2$ )

$$
\frac{V_{o}}{V}=\mathrm{F} \epsilon \times 10^{-3}
$$

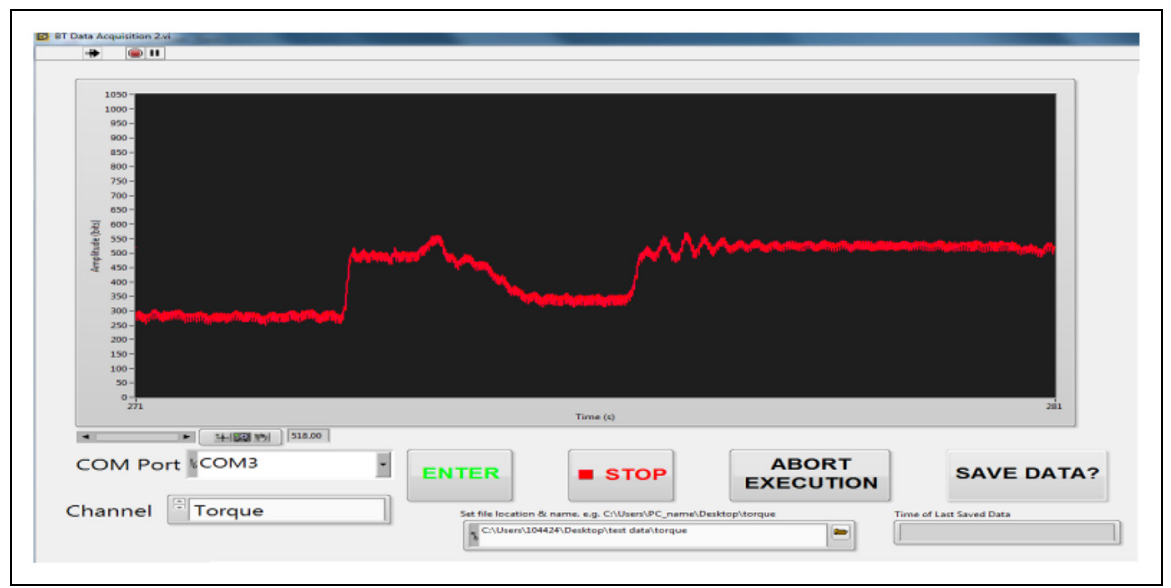

Figure 7. The PC display panel for data acquiring, variables changing in LabVIEW. 


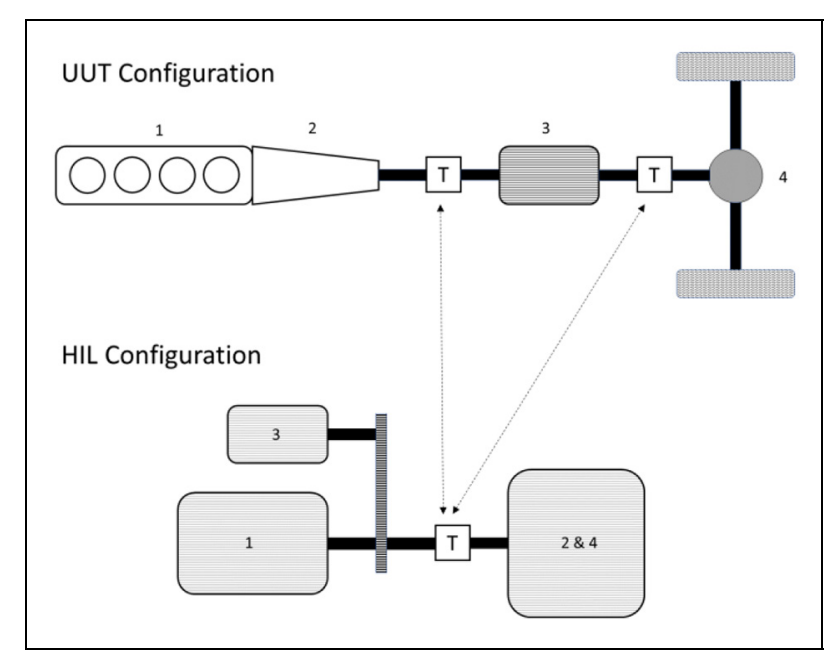

Figure 8. The simple HIL configuration (below) emulating the UUT (above). The torque transducer can be moved between the configurations to eliminate the relative error. HIL: hardware-in-loop; UUT: Unit Under Test.

\section{Module testing}

The built module was tested against a commercially available torque sensor which has been extensively used in the past. The commercially available sensor uses a stationary inductive loop to provide power to a rotating assembly. The commercially available torque sensor and the low-cost sensor were installed on a continuous rigid shaft. One end of the shaft is connected to a motor to provide driving torque, and the other end is connected to an eddy brake to provide a sink, inducing a uniform torsion across the shaft which should be read identically by both sensors. The commercial sensor uses the inductive antenna to provide both power and signal telemetry, which passes through to a digital receiver unit. The receiver unit may be powered by $12 \mathrm{~V}$ DC or mains power. The units are independently calibrated, allowing the output signal from the low-cost sensor to be compared to the commercially available unit. The setup allows the performance of the low-cost sensor to be benchmarked against the more expensive, commercially available option for frequency response. Because the low-cost sensor uses an onboard ADC and wireless digital communication, the signal-to-noise ratio cannot be benchmarked against the commercial unit.

Following from this initial testing, which shows the low-cost sensor performs as required, the sensor is deployed into the powertrain test facility and paired with a wide array of instrumentation, which has been developed for experimental validation of the powertrain simulation. This validation step has been detailed previously in literature. ${ }^{12,13}$ The goal, in this case, is to use HIL testing to validate a powertrain model which will allow accurate, high-fidelity hardware emulation of vehicle behaviour during gear changes in vehicles equipped with MTs. The portability of the unit is used to our advantage. Because the unit is swapped between the Unit Under Test (UUT) and the HIL test bed, response checks against a second unit are not required. Instead, calibration checks only are required to account for variability in strain gauge manufacturing. The approach radically reduces relative error and allows direct comparison of results. The HIL setup allows quick and easy investigation of a variety of torquesmoothing solutions, significantly accelerating the development process. The UUT is described in Figure 8. It consists of a four-cylinder petrol engine (1), manual gearbox (2), shaft-mounted brushless DC (BLDC) traction motor (3), and the differential and road wheel assembly representing the loads (4). The HIL apparatus is analogous. It is based upon an induction motor (1), emulating the tractive forces from the four-cylinder petrol engine and an eddy brake (2 and 4) which acts as the loads and losses (road loads multiplied through the gearbox). A BLDC traction motor (3) identical to that installed in the UUT is connected to the induction motor by a belt drive. Referring to Figures 9 and 10, the induction and BLDC motors are controlled by an accurate real-time virtual driver and vehicle model. The eddy brake is similarly controlled by the virtual vehicle model and load model. The traction drives and road load components are connected rigidly using the instrumented shaft, allowing direct comparisons to be made to the UUT.

A supervisory controller is implemented using dSPACE ControlDesk combined with a MicroAutoBox II controller unit. The supervisory controller, in turn, commands an ABB motor controller which generates direct torque commands for the IM, emulating the vehicle model. The supervisory controller also controls the eddy brake through a power supply, which provides aerodynamic loss, inertial resistance and rolling loss loads. The supervisory controller is informed by a model based on real data acquired from on-road vehicle testing, providing accurate torque profiles, vehicle speed targets and gear-change points. The controller and software use a fixed step-size routine to ensure continuous real-time synchronization is maintained - this is implemented using the MATLAB realtime workshop as well as the dSPACE real-time interface (RTI).

\section{HIL results}

For testing on the HIL bench, the module is mounted on a through-shaft connecting both the source and sink end of the rig, concurrently with another sensor (ATi 2000). These sensors enable us to capture the transient torque at the same shaft, such as the transmission output shaft. The torsional vibration characteristics of the test rig were determined from both sensors and compared. Results shown in Figure 11 showed good agreement to the ATi (commercial) sensor, with the only noticeable variation being a slight negative offset, particularly noticeable at $3 \mathrm{~s}$ and likely due to physical variation in strain gauge bonding, as well as slight 


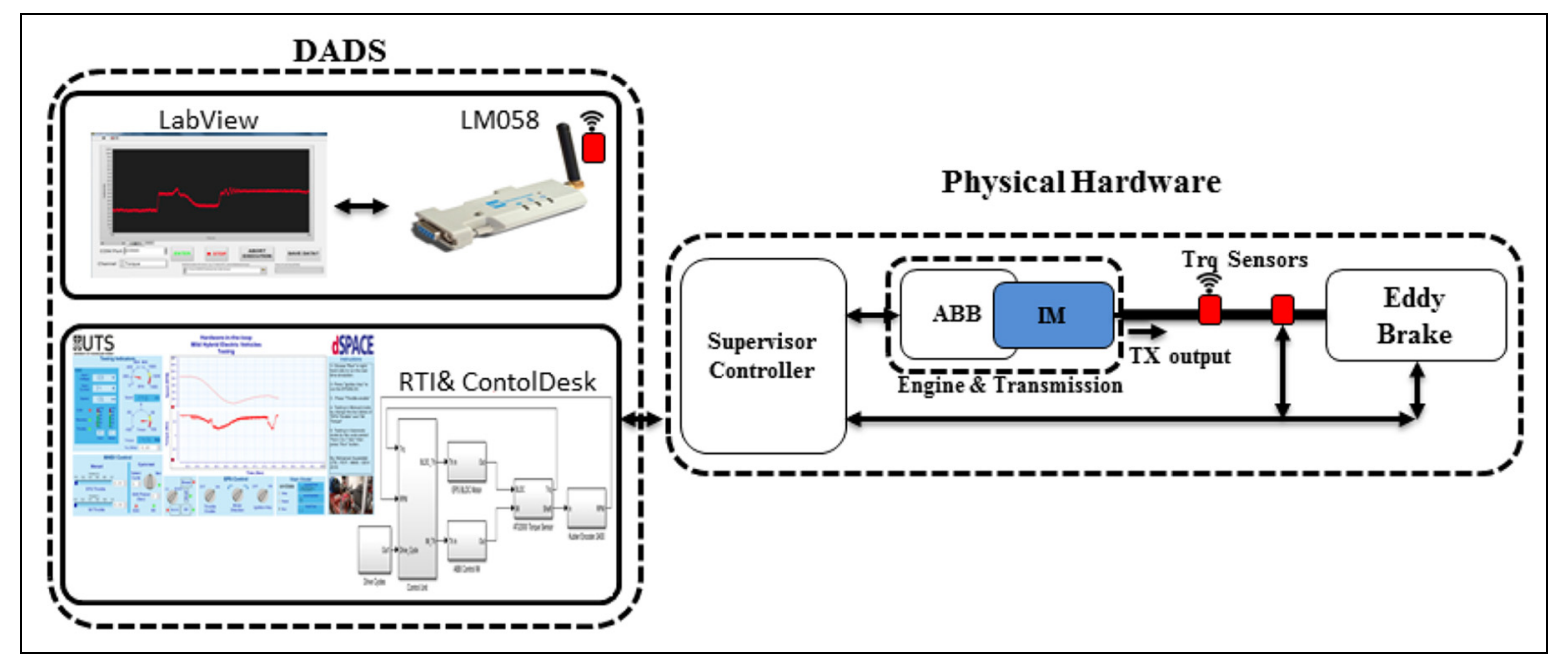

Figure 9. HIL test bed controller structure.

HIL: hardware-in-loop; RTI: real-time interface DADS: Data Acquisition and Distribution System; ABB: ABB motor drive; UTS: University of Technology Sydney; IM: Induction Motor; TX: Transmission.

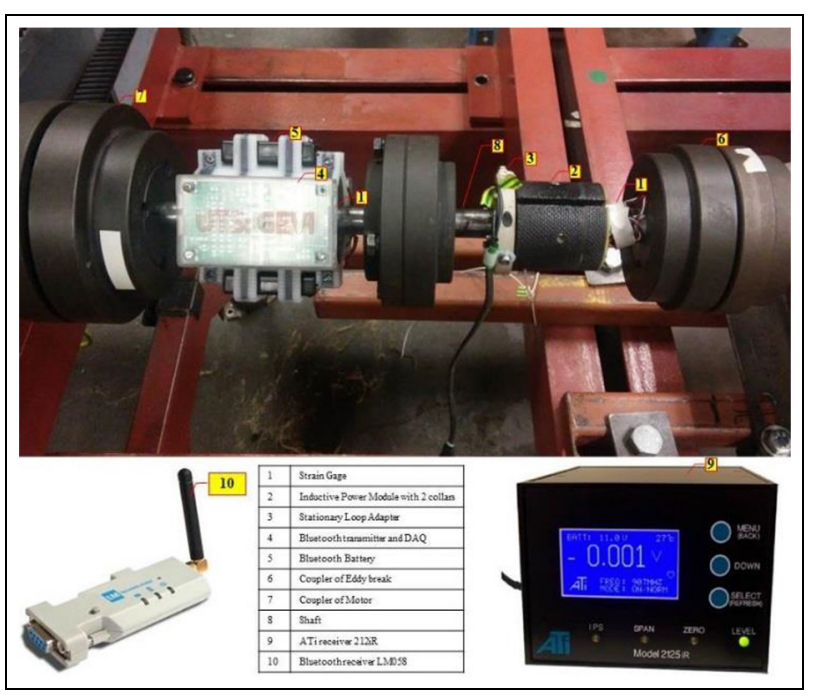

Figure 10. Torque sensors.

smoothing of the data due to sample-pair averaging. Neither of these variations are significant. The data from both sensors validate the ability of the HIL bench to accurately reach target torques required to simulate the gear shift profile modelled on our prototype vehicle. The bluetooth sensor is thus suitable for experimental investigations of the transient characteristics of transmissions.

\section{Powertrain selection}

As previously discussed, the powertrain was selected after power flow analysis and benchmarking calculations yielded desired characteristics and vehicle parameters for a typical B/C-segment vehicle in our target market. An extensive market study found the closest powertrain to these characteristics and parameters was that of a 1990-1995 Mazda MX-5 (Miata), equipped with a manual five-speed transmission, as shown in Figure $12 .{ }^{14}$ For the purpose of our hybridization study, the body style is irrelevant; the weight and aerodynamic performance are similar enough to benchmarked parameters, and the powertrain and emissions profile is highly representative of many vehicles being sold new in developing regions. The vehicle uses a lowtech four-cylinder engine with power output and emissions characteristics typical of most B- and C-segment vehicles in use in our target market. In addition to this, simple body and rear drive powertrain made this vehicle choice appropriate as a basis for conversion to a petrol-electric hybrid, given the ease with which the modifications may be made, and parts may be obtained. Being a common vehicle, this also will allow future development, including laboratory testing, to continue using a readily available vehicle that matches well with physical characteristics used in simulations. For these reasons, the powertrain was considered ideal for this project.

\section{Simulation model development}

Simulation of the system was conducted in the Simscape/Simulink environment, utilizing the Simscape and SimDriveline toolbox to develop a software model. The model is based on a Mazda MX-5 (Miata) powertrain, which itself was selected as it bore a high level of similarity to our hypothetical ideal powertrain, determined through a power flow analysis and performance benchmarking calculations to determine component characteristics, and vehicle parameters. Basing the model on an existing powertrain greatly simplifies the validation process, allowing quicker development. The model includes elements of the engine, flywheel, clutch plate, pressure plate, transmission gears and shafts, differential, driveshafts, wheels and vehicle inertia. At its core is an eight degree-of-freedom (DOF) vehicle 


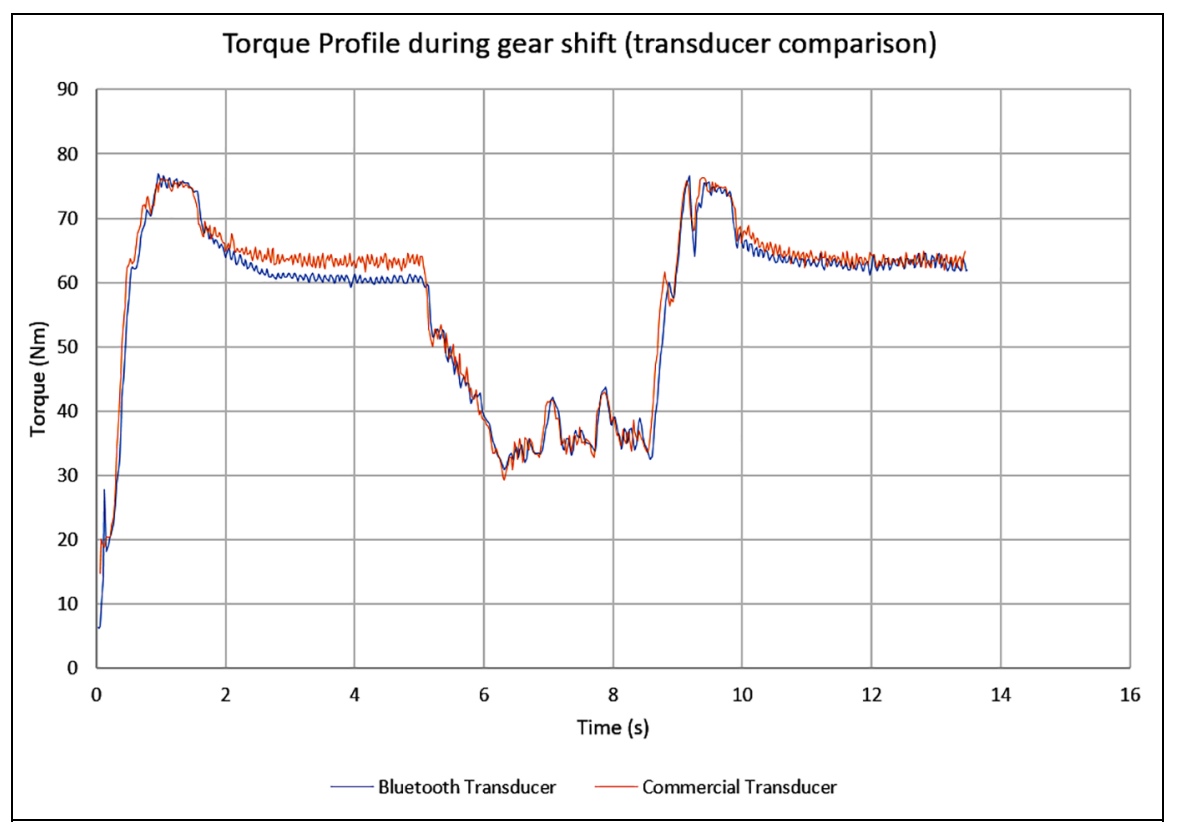

Figure I I. Torque profile emulation data (including torque fill-in) from the HIL bench, obtained using the commercial transducer and the UTS bluetooth transducer inline. HIL: hardware-in-loop.

Table 2. Vehicle global specifications.

\begin{tabular}{ll}
\hline Parameter & Specifications \\
\hline ICE & $1.6 \mathrm{~L}, 70 \mathrm{~kW}$ at $5000 \mathrm{r} / \mathrm{min}$ \\
Vehicle mass & $1200 \mathrm{~kg}$ \\
Frontal area & $3 \mathrm{~m}^{2}$ \\
Tyre rolling radius & $0.312 \mathrm{~m}$ \\
Rolling resistance & 0.015 \\
Manual transmission & $3.58 \mathrm{I}, 2.022, \mathrm{I} .4, \mathrm{I} .03,0.94$ \\
Final drive ratio & 4.06 \\
\hline
\end{tabular}

ICE: Internal Combustion Engine.

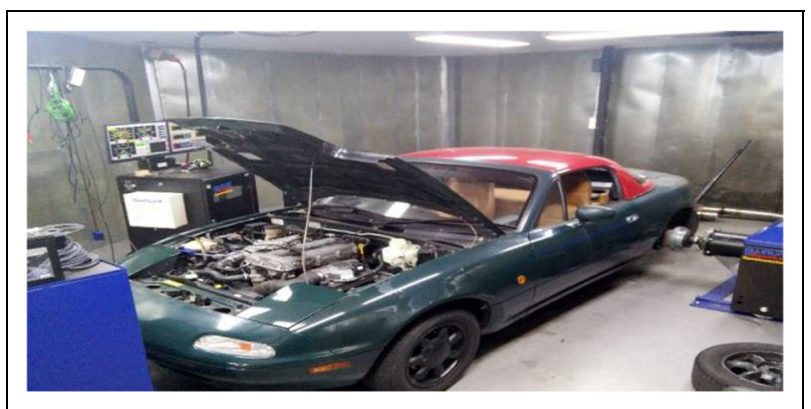

Figure 12. Mazda powertrain test rig.

dynamics model created in Simulink. More features are shown in Table 2. The model is then studied in terms of its operational performance by submitting it to various drive cycles using the Advanced Vehicle Simulator (ADVISOR). The output results of the simulation are then compared to data collected from the torque sensor and other sensors affixed to the UUT. The drive cycle testing methodology is well-described in literature. . $^{215-17}$

\section{The overall structure of the powertrain model}

A high-level view of the simulation environment is shown in Figure 13. The simulation environment fully describes a conventional vehicle in its testing environment and implements a forward-looking modelling approach, wherein the driver model is used to provide throttle, braking, gear selection and clutch position input to the simulation, according to a pre-determined vehicle drive cycle (vehicle speed vs time). The simulation output includes vehicle speed, which is used as the feedback information for the driver model. The simulation includes real, measured values for vehicle parameters, specifications and performance requirements. Virtual instrumentation is also included, allowing simple comparison between software modelling, HIL simulation and prototype testing results.

The vehicle dynamics building block includes basic physical information regarding the vehicle, such as vehicle mass and mass distribution, drag coefficient, frontal area, mechanical, windage, and rotational losses, inertias, and a simple longitudinal tyre and contact patch model. ${ }^{18,19}$ These factors are implemented from the Simscape toolbox in MATLAB, in accordance with equation (2)

$$
T_{v}=\left(f_{R} M_{v} g \cos \varnothing+M_{v} g \sin \varnothing+\frac{1}{2} C_{D} \rho A_{v} V_{v}^{2}\right) r_{w}
$$




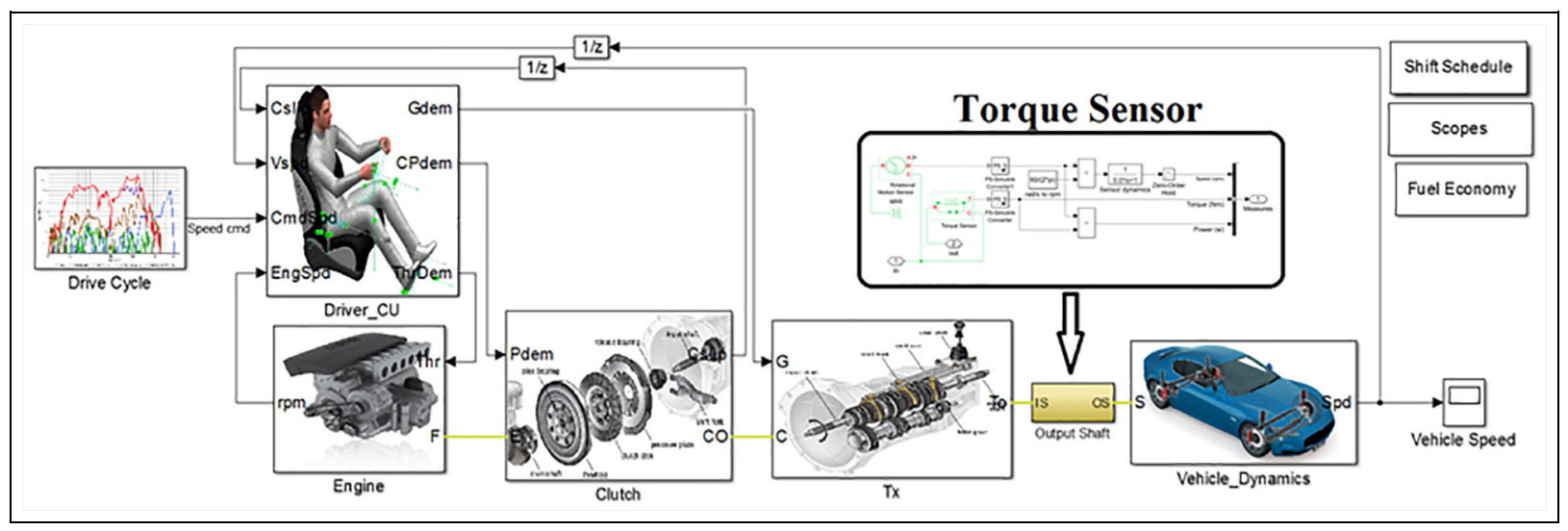

Figure 13. A high-level view of the CV simulation environment. $\mathrm{CV}$ : conventional vehicle.

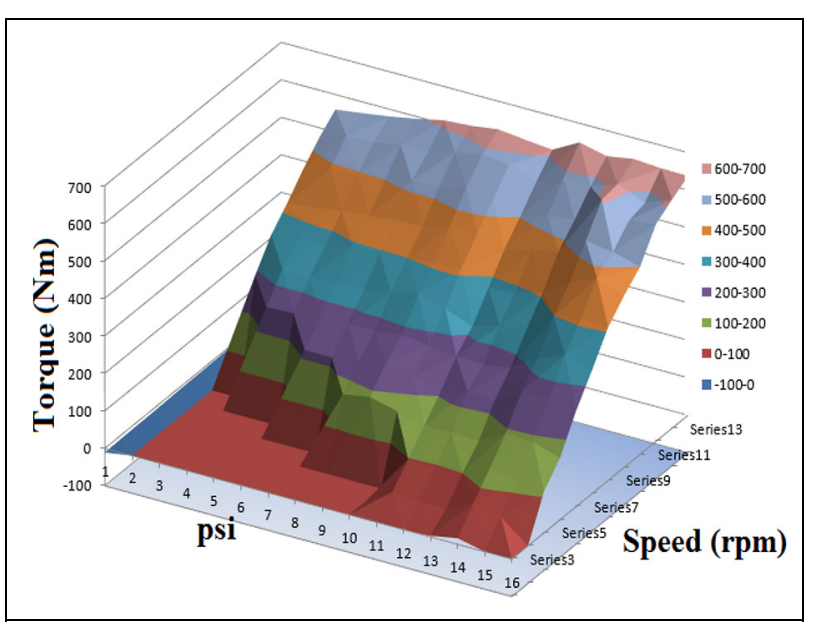

Figure 14. Engine characteristics, mapping engine torque (measured at the driven wheel) and engine speed against manifold absolute pressure. Engine crankshaft torque is calculated using a multiplication factor of 0.232 .

where $T_{v}$ is vehicle torque; $V_{v}, \mathrm{~m}, A_{v}$ are the speed, mass and frontal area of the vehicle; $r_{w}$ is the wheel radius; $f_{R}$ is the rolling resistance (friction) coefficient; $C_{D}$ and $\rho$ are the drag coefficient and air density; $\varnothing$ is the road grade; and $g$ is gravitational acceleration.

Appropriate simplifications and assumptions were built into the Simscape, simulation model. These simplifications reduce the computational demand and allow the simulation to reliably run in real time with sufficiently small step size. The simplifications extend to the use of lumped inertia models of vehicle components, and the use of a 'Generic Engine' component available within the SimDriveline package, which is a simple engine model that employs user-defined engine parameters to provide output torque to drive the simulation. In this implementation, the engine parameters consisted of a three-dimensional lookup table of engine torque, based on measured data from the physical test unit. The table is shown in Figure 14. This development strategy has been successfully used in the prior literature. $^{2}$

\section{Torque hole and shift process analysis}

Data acquired from the low-cost torque sensor enable the analysis of the shift process, from which an understanding of effective improvements to the gear shifting characteristics can be derived. The physical gear shift process requires the disengagement of a single dry clutch plate, actuation of a selector fork to deselect a gear and select the new gear, and re-engagement of the clutch plate. The gear deselection and selection process is completed while the powertrain is decoupled from the road wheels, and the inertia of the gear pinions is negligible compared to the vehicle inertia. Therefore, the deselection and selection process may be neglected in the analysis, save for understanding the effect of the varying ratios on speed and torque discontinuities when the clutch is engaged. Therefore, the gear shift process is divided into three phases, based on the position of the clutch plate. The first phase is characterized by a rapid reduction in torque transmission to zero. It is correspondent with the actuation of the clutch plate from fully engaged to disengaged. The engine is rapidly decoupled from the gearbox, but gear ratio remains constant. Vehicle acceleration begins to decrease due to parasitic losses and environmental forces. This phase coincides with the beginning of the torque hole. The second phase is characterized by zero torque transmission and represents the floor of the torque hole. It is correspondent with a fully disengaged clutch plate. In this phase, the gear is unloaded, and a new gear may be freely selected. A minor torque oscillation can be observed as the new gear is selected and accelerated to the same speed as the output shaft by synchronizers. The final phase is characterized by significant torque oscillations as the powertrain is re-engaged to the vehicle through the re-engagement of the clutch plate. This re-engagement results in speed and inertia discontinuities becoming equalized, through slippage of the clutch friction face against the flywheel face during the reengagement. As the clutch is re-engaging, the engine throttle is re-opened, allowing the engine to supply torque to the system to achieve the target acceleration. 


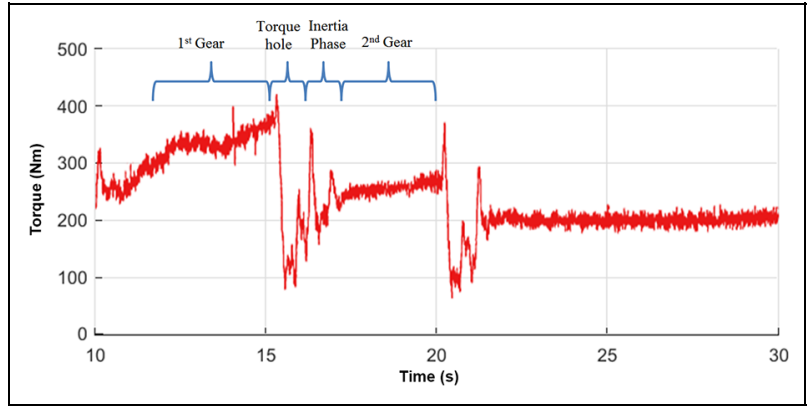

Figure 15. Actual measured half shaft torque with fill-in, showing the different phases of the gear change. ${ }^{8}$

When the clutch is fully engaged, a constant speed ratio equal to the selected gear ratio is achieved, and speed proportionality applies across the whole system with no discontinuity. ${ }^{20}$

A number of factors influence the shift process. These include the engine torque value immediately before the shift process, as well as final target torque, clutch feed-in and feed-out rate, and dynamic friction coefficient of the clutch interface. Figure 15 shows an example of measured shaft torque, with a torquesmoothing motor providing 'fill-in' during the gear shift event. ${ }^{21}$ When the clutch is less-than-fully engaged, a speed differential is introduced through slippage or complete disengagement of the clutch face. The output torque varies sharply during a clutch slip and is always zero (or close to zero, as some drag friction may provide an insignificant torque path) when the clutch is fully disengaged. The torque hole is defined by its width, which is the time from the beginning of the clutch disengagement process to the end of the reengagement process, and its depth, which varies as the slope from the initial torque to the final target torque, in reference to zero torque (in a conventional vehicle) or the available filling torque (in a torque-smoothing powertrain). ${ }^{22}$ Without torque-filling, if the width increases, the vehicle decelerates more significantly. However, decreasing the width of the torque hole too significantly can cause a step-change in torque, which is felt as an uncomfortable jerk by vehicle occupants.

\section{Simulation results}

The simulation of the vehicle is focused on understanding and improving the torque hole during gear changes. Selected data obtained from the simulation are shown in Figure 16, which describes the shift process in both a conventional vehicle and the torque-filling mild hybrid electric vehicle, when upshifting on identical drive cycles from second to fifth gear. The various torsional excitations on the output shaft are demonstrated in both the conventional vehicle simulation and the torque-filling simulation. The excitations are resultant from the clutch re-engagement process and the gear selection process. Of these, the clutch re-engagement

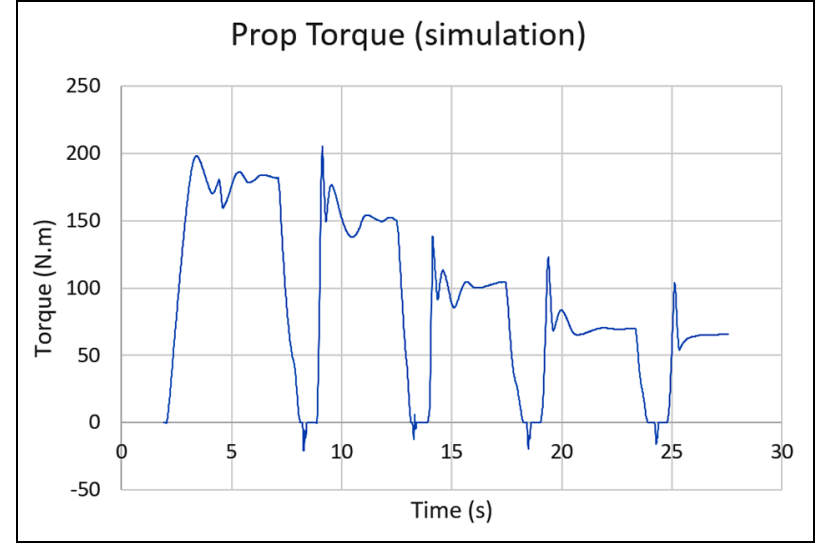

Figure 16. Torque profile during constant-throttle acceleration cycle.

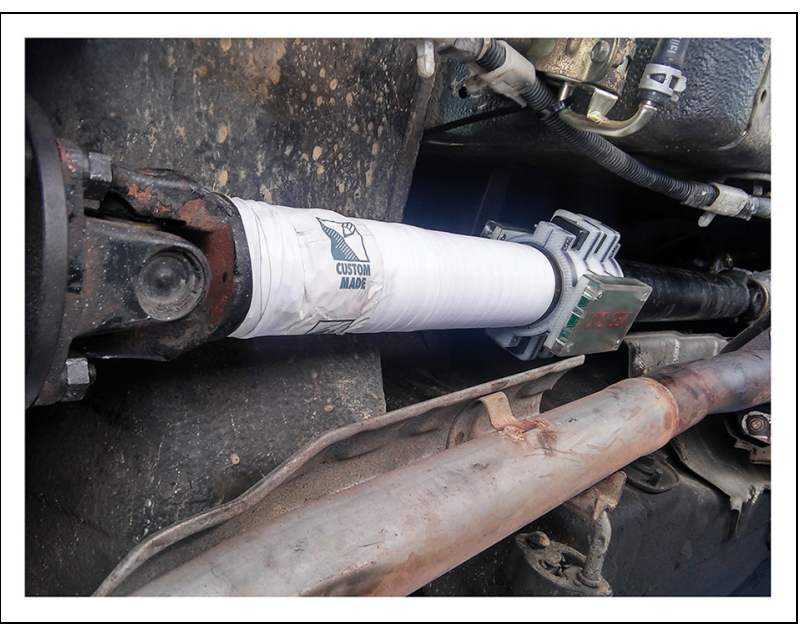

Figure 17. The low-cost torque sensor installed on the prototype powertrain. Strain gauges are covered over using a lightweight shield for mechanical protection.

excitation is markedly reduced by the introduction of the torque-filling process, showing a reduction of $175 \mathrm{~N} \mathrm{~m}$ compared to the conventional vehicle simulation. The torque hole is also reduced in its depth. This initial simulation demonstrates the capability of the torque-filling powertrain and suggests further development would be promising.

\section{Comparative results}

Experimental testing was conducted using a hubmounted dynamometer testing facility, which provides excellent repeatability characteristics as the elimination of the road-tyre interface allows drive cycles to be programmed and run at will, and interfaces with data acquisition to simply and quickly instrument an entire vehicle powertrain. Figure 17 shows the Mazda test vehicle, with the low-cost torque sensor installed on the prop shaft for field testing. The sensor located at this point allows the acquisition of high-quality data related 


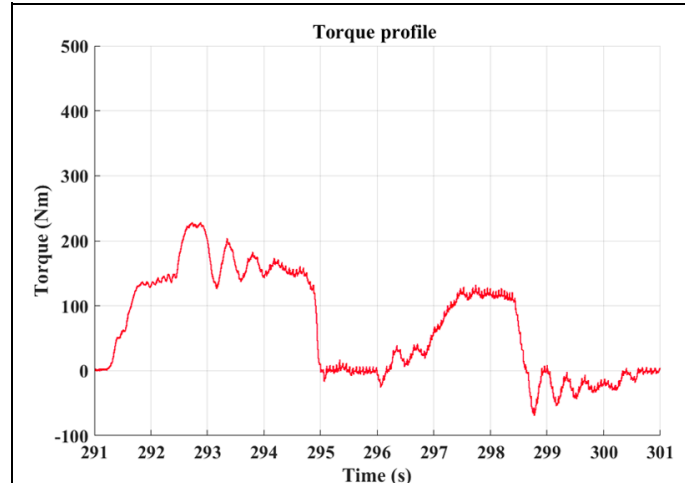

(a)

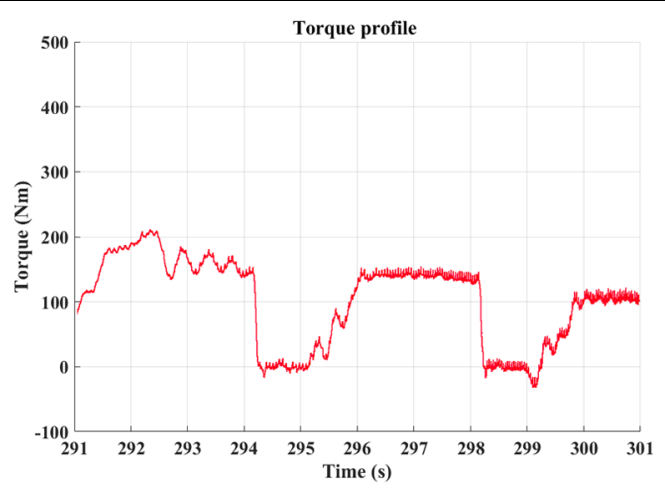

(b)

Figure 18. Real measured torque on the prop shaft: (a) gear change from first to second and (b) gear change from first to third.

to transient torsional vibrations and excitations, which can be used to improve the fidelity of our virtual and HIL simulations, as well as validate results from laboratory-based development. The torsional vibration characteristics of the vehicle were determined and compared to those obtained from a simulation car. The initial field test results demonstrate that the fidelity of the HIL simulation is sufficiently close to the prototype vehicle to enable understanding and control of significant torsional excitations from the key gear-change events. The system, including the low-cost torque sensor, is thus suitable for experimental investigations of the transient characteristics of transmissions.

The aim of the testing was to replicate the simulated and HIL testing, conducted previously and described earlier. The physical testing will then be used to improve modelling techniques to allow solutions to be rapidly evaluated before deployment. There are several variables that are not accounted for in the simulation. These include environmental temperature and pressure, for which standard temperature and pressure are substituted, and the previously described 'generic engine' block, which does not include environmental effects or effects of engine temperature, fuel temperature and other parameters pertinent to engine performance. For initial testing, these variables may be neglected; providing the appropriate torque targets are reached, the kinematic performance of the drivetrain downstream of the engine is largely independent of temperature, although greater fidelity could be added by inserting a gearbox oil temperature and fluid drag model, as well as a clutch disc temperature model.

The initial testing involved programming the dynamometer to provide a speed-dependent load to simulate rolling and aerodynamic losses, then 'driving' the vehicle using a human driver to replicate the testing provided. Various driving aids were provided, including a real-time output of speed and torque, to enable the driver to drive to the drive cycle as accurately as possible. Figure 18 shows an extract of the torque results, typical of those obtained from the low-cost torque sensor during a test run. The transient torsional characteristics exhibit many similarities to the simulation. These include the small negative torque artefact during the gear selection event caused by synchronizer friction and the torque oscillation immediately preceding the full re-engagement of the clutch. In the simulation, the magnitude of both these events is significantly higher than in the physical validation. In comparison to the simulation, the physical validation shows a higher level of underdamped torsional vibration in the period immediately following the full re-engagement of the clutch. This is likely due to two factors: the first is differences in clutch feed-in technique between the simulation (which feeds the clutch in linearly) and the driver (who feeds the clutch in to maximize smoothness and comfort). The second is variances between spring and damping characteristics of the drivetrain mounting points in the UUT and the simulation. The spring stiffness and damping coefficients of these mounts were estimated in the simulation rather than measured.

The ability to quickly redeploy the low-cost torque sensor from HIL testing to physical testing greatly simplifies instrumentation and provides an added level of confidence in measured values. The sensor performs very well for the intended application, although there are some minor issues. These issues include occasional data packet corruption during bluetooth transmission, and the periodic interruption of data flow, caused by a software handshaking issue. However, the sensor is highly adapted for the purpose of transient torsional vibration measurement in automotive settings, performing reliably and integrating well with existing data acquisition.

\section{Vehicle jerk estimation using wireless torque sensor}

One of the key variables used in shift transient analyses is the vehicle jerk. This is the time rate of change in acceleration and a commonly used measurement of gear shift harshness. This sensor is particularly suited to such 


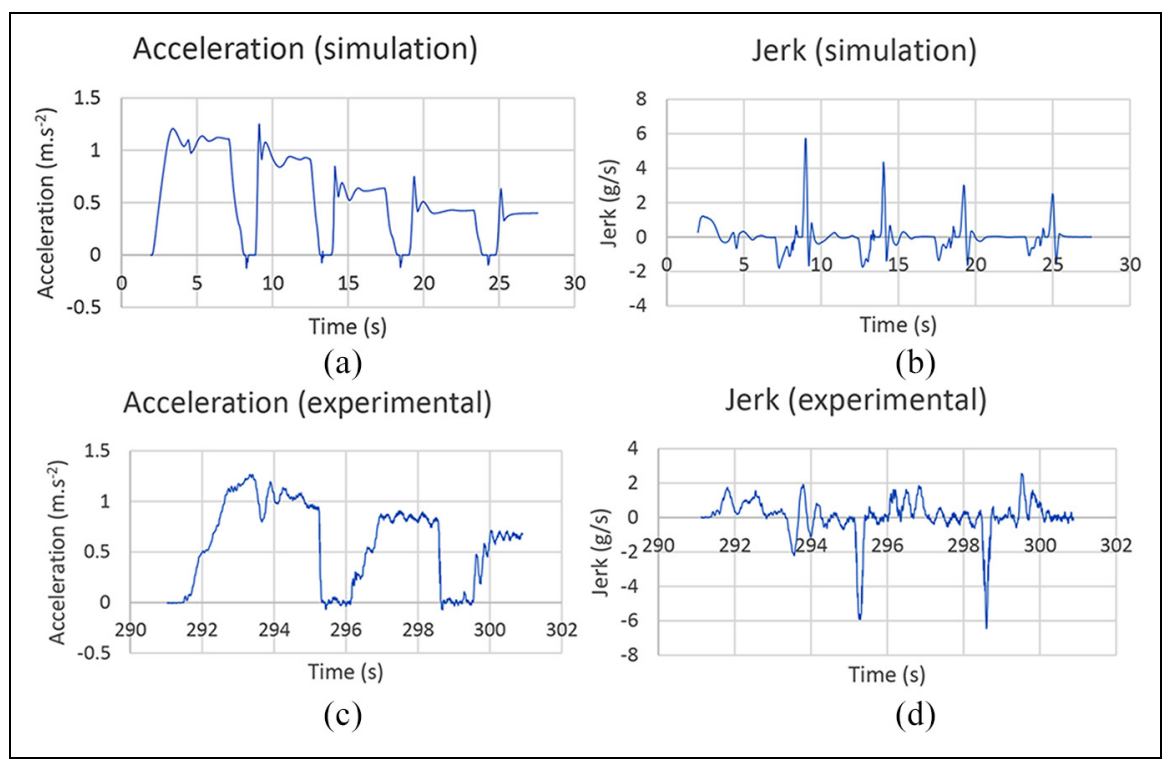

Figure 19. Comparative jerk and acceleration results: (a) vehicle acceleration obtained numerically from simulation, (b) jerk obtained numerically from simulation, (c) measured acceleration from comparative experiment and (d) experimental jerk results obtained using the numerical derivative method.

an investigation on rolling chassis dynamometers as the vehicle itself is stationary.

In practice, vehicle jerk can be estimated using the numerical derivative of vehicle acceleration. This estimation is often achieved with accelerometers on the road, but cannot be easily achieved on rolling chassis dynamometers. Vehicle data obtained using the torque transducer in a dynamometer setting are presented in Figure 19. The data consist of calculated acceleration based on dynamometer head speed, and jerk, calculated from the torque data obtained from the sensor. The experimental results are then compared against the software model of the vehicle, which is run through a similar drive cycle (namely, a gentle acceleration cycle from gear 1 and zero road speed). The aim of this is an exercise to provide validation of the software model against the developed prototype.

Comparative results between the simulation and experiment show similar characteristics. Notably, the magnitude of peak jerk, as well as oscillation frequencies, are well-matched. Peak jerk falls within the 4-6g/s range in 1-2 and 2-3 gear shifts, and the primary frequency of $2.5 \mathrm{~Hz}$ is measured in both. The major difference between experimental and simulated results is in the direction and timing of the major jerk event during gear change. Where the simulation shows a positive jerk caused by the clutch re-engagement event, the experimental result shows a negative jerk caused by the clutch disengagement. The cause of the difference is presented clearly by examining the rate of change of acceleration on each side of the gear-change event. Where in the simulation, the clutch disengagement is characterized by a more gradual loss of drive torque, the opposite is true of the experimental result, which shows the disengagement to be represented by a near vertical rate of change of acceleration. On the reengagement event, the reverse is true, with a sharp increase in acceleration in the simulated event contrasting against a gradual increase in the experiment.

The results are constructive, in that they provide validation of the vehicle model by confirming natural oscillation frequency and the magnitude of jerk events. The inverted direction of jerk is also constructive as it identifies further work required to refine the clutch disengagement and re-engagement model.

The process shows that the low-cost bluetooth torque transducer can be successfully used in an HIL rapid prototyping setting to reduce development time and cost by providing directly comparable results across different test platforms.

\section{Conclusion}

In this paper, we have described the development, testing, validation and implementation of a wireless torque measurement device that is well-adapted to the purpose of obtaining transient torsional vibration and excitation characteristics for automotive powertrain development. The sensor was modelled in a virtual simulation environment, developed and physically installed in an HIL development test-bench, and easily and quickly transplanted to a prototype UUT for physical validation. Results were also compared against software simulation to provide software validation. This work highlights the advantage of this low-cost torque sensor, and the novelty of particular design characteristics, such as it is low-profile, the robustness of its 3D printed housing, its onboard ADC and signal conditioning, and the lack of any requirement for wiring of data or power. These features were not found in any equivalent 
commercially available torque sensor, and significantly aided development, and allowed the single low-cost sensor module to be used for all physical development and testing work, dramatically reducing cost and improving workflow and results.

The results obtained during HIL and physical testing allowed development of the HIL system to be rapidly improved, and use of the same device between test platforms eliminated a source of error, as well as eliminating the need for providing separate torque data acquisition devices in different environments. The torque sensor had sufficient performance to provide highquality results for analysis and validation of software simulation and HIL, which in turn can be used to confidently develop the torque-filling function on the powertrain under development with a significantly reduced need for field testing.

Some development work on the sensor remains, principally regarding the bluetooth communication. Improving or making better use of available bandwidth would improve its flexibility. The device has been shown to be physically capable of operating on a shaft spinning at high speed, and the ADC is capable of sampling at appropriate speeds. However, the sample rate has been artificially reduced such that the performance of the device is merely acceptable for testing at such speeds, rather than ideal. Improving bandwidth utilization would allow the artificial reduction in sampling rate to be removed. Further development work could also focus on the stability of the bluetooth link and ensuring that periodic handshaking does not interrupt data flow, as well as investigating the causes of corrupt data packets and reducing their occurrence.

\section{Declaration of conflicting interests}

The author(s) declared no potential conflicts of interest with respect to the research, authorship and/or publication of this article.

\section{Funding}

The author(s) received no financial support for the research, authorship and/or publication of this article.

\section{ORCID iD}

Mohamed Awadallah (D) https://orcid.org/0000-00022317-4527

\section{References}

1. Awadallah M, Tawadros P, Walker P, et al. Dynamic modelling and simulation of a manual transmission based mild hybrid vehicle. Mech Mach Theory 2017; 112: 218-239.

2. Awadallah M, Tawadros $\mathrm{P}$, Walker $\mathrm{P}$, et al. Comparative fuel economy, cost and emissions analysis of a novel mild hybrid and conventional vehicles. Proc IMechE, Part D: J Automobile Engineering 2018; 232: 1846-1862.
3. Zhang N, Chapman C and Crowther A. Development of a novel wireless transducer for measuring the transient torque of an automotive powertrain. In: Mathew J, Kennedy J, Ma L, et al. (eds) Engineering asset management. London: Springer, 2006, pp.1056-1062.

4. Awadallah M, Tawadros P, Walker P, et al. A low-cost and novel approach in gearshift control for a mild-hybrid powertrain. In: IEEE transportation electrification conference and expo (ITEC), 2017, Chicago, IL, 22-24 June 2017, pp.754-760. New York: IEEE.

5. Hutchinson T, Burgess $S$ and Herrmann G. Current hybrid-electric powertrain architectures: applying empirical design data to life cycle assessment and whole-life cost analysis. Appl Energ 2014; 119: 314-329.

6. Kuo K-L. Simulation and analysis of the shift process for an automatic transmission. World Acad Sci Eng Technol 2011; 52: 341-347.

7. Sun $\mathrm{Z}$ and Hebbale K. Challenges and opportunities in automotive transmission control. In: Proceedings of the 2005 American control conference, 2005, Portland, OR, 8-10 June 2005, pp.3284-3289. New York: IEEE.

8. Baraszu RC and Cikanek SR. Torque fill-in for an automated shift manual transmission in a parallel hybrid electric vehicle. In: Proceedings of the 2002 American control conference (IEEE Cat. No. CH37301), Anchorage, AK, 8-10 May 2002, Vol. 2, pp.1431-1436. New York: IEEE.

9. Walker PD and Zhang N. Active damping of transient vibration in dual clutch transmission equipped powertrains: a comparison of conventional and hybrid electric vehicles. Mech Mach Theory 2014; 77: 1-12.

10. Zhou X, Walker P, Zhang N, et al. Numerical and experimental investigation of drag torque in a two-speed dual clutch transmission. Mech Mach Theory 2014; 79: 46-63.

11. Wagner G. Application of transmission systems for different driveline configurations in passenger cars. SAE technical paper 2001-01-0882, 2001.

12. Awadallah M, Tawadros $\mathrm{P}$, Walker $\mathrm{P}$, et al. Hardwarein-the-loop simulation for the design and testing of motor in advanced powertrain applications. In: 2018 IEEE 27th international symposium on industrial electronics (ISIE), Cairns, QLD, Australia, 13-15 June 2018, pp.817-824. New York: IEEE.

13. Awadallah M. A mild hybrid vehicle control unit capable of torque hole elimination in manual transmissions. $\mathrm{PhD}$ Thesis, Faculty of Engineering and IT, University of Technology Sydney, Sydney, NSW, Australia, 2017.

14. Takao K and Toshihiko H. Vehicle development through 'Kansei' engineering. SAE technical paper 0148-7191, 2003.

15. Awadallah M, Tawadros $\mathrm{P}$, Walker $\mathrm{P}$, et al. Eliminating the torque hole: using a mild hybrid EV architecture to deliver better driveability. In: 2016 IEEE transportation electrification conference and expo, Asia-Pacific (ITEC Asia-Pacific), Busan, South Korea, 1-4 June 2016, pp.173-179. New York: IEEE.

16. Awadallah $\mathrm{M}$, Tawadros $\mathrm{P}$, Walker $\mathrm{P}$, et al. A comparative fuel analysis of a novel HEV with conventional vehicle. In: 2017 IEEE 85th vehicular technology conference (VTC Spring), Sydney, NSW, Australia, 4-7 June 2017, pp.1-6. New York: IEEE.

17. Awadallah M, Tawadros $\mathrm{P}$, Walker $\mathrm{P}$, et al. Impact of low and high congestion traffic patterns on a mild-HEV performance. In: SAE 2017 international powertrains, 
fuels \& lubricants meeting, Beijing, China, 16-19 October 2017. Warrendale, PA: SAE International.

18. Borhan HA, Vahidi A, Phillips AM, et al. Predictive energy management of a power-split hybrid electric vehicle. In: American control conference, 2009. ACC '09, St Louis, MO, 10-12 June 2009, pp.3970-3976. New York: IEEE.

19. Hartani K, Miloud Y and Miloudi A. Improved direct torque control of permanent magnet synchronous electrical vehicle motor with proportional-integral resistance estimator. J Electr Eng Technol 2010; 5: 451-461.
20. Galvagno E, Velardocchia M and Vigliani A. A model for a flywheel automatic assisted manual transmission. Mech Mach Theory 2009; 44: 1294-1305.

21. Baraszu RC and Cikanek SR. Hybrid electric vehicle with motor torque fill in. US6629026B1 Patent, 2003.

22. Tona P, Gautier P and Amari R. Modeling and control of a mild-hybrid city car with a downsized turbo-charged $\mathrm{CNG}$ engine. In: Proceedings of advanced vehicle control symposium (AVEC), Kobe, Japan, 6-9 October 2008. Society of Automotive Engineers Japan.

\section{Appendix I}

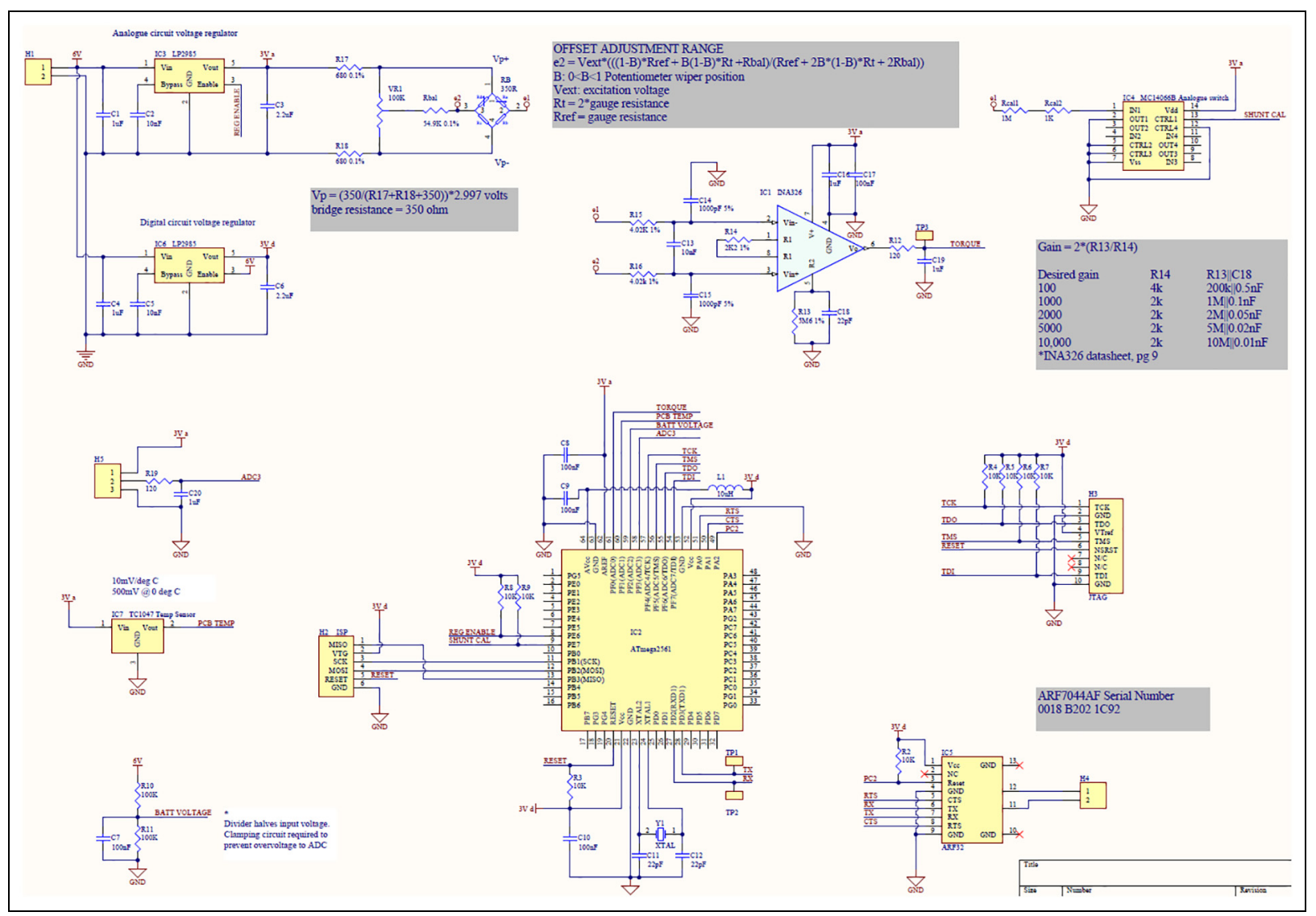

Figure 20. BT torque sensor schematic.

BT: bluetooth. 